\title{
BMJ Open Primary healthcare usage and morbidity among immigrant children compared with non-immigrant children: a population-based study in Norway
}

\author{
Lars T Fadnes, ${ }^{1,2}$ Kathy Ainul Møen, ${ }^{1}$ Esperanza Diaz ${ }^{1,3}$
}

To cite: Fadnes LT, Møen KA, Diaz E. Primary healthcare usage and morbidity among immigrant children compared with non-immigrant children: a population-based study in Norway. BMJ Open 2016;6:e012101. doi:10.1136/bmjopen-2016012101

- Prepublication history and additional material is available. To view please visit the journal (http://dx.doi.org/ 10.1136/bmjopen-2016012101).

Received 30 March 2016 Revised 8 August 2016 Accepted 16 August 2016

CrossMark

\footnotetext{
${ }^{1}$ Department of Global Public Health and Primary Care, University of Bergen, Bergen, Norway

${ }^{2}$ Department of Clinical Dentistry, University of Bergen, Bergen, Norway ${ }^{3}$ Norwegian Centre for Minority Health Research, Norway
}

Correspondence to Dr Lars T Fadnes; lars.fadnes@uib.no

\section{ABSTRACT}

Objectives: Health status, disease spectrum and use of healthcare have been reported to vary across groups of migrants and according to the different phases of migration. However, most studies are conducted among adults. This study assesses usage of primary healthcare $(\mathrm{PHC})$ by children with immigrant background compared with non-immigrant children in Norway and describes their relative morbidity burden.

Design: Population-based retrospective cohort study. Setting: This study used 3 linked population-based registers in Norway for children under 18 years of age in 2008.

Main exposure and outcome measures:

Immigrants were defined as children with both parents born abroad, and further classified into first and second generation, and according to the World Bank income categories of their parents' country of origin. Usage and morbidity were assessed with negative binomial regression and logistic regression analyses, respectively. Further, populationattributable fraction analyses on $\mathrm{PHC}$ visits were conducted to estimate the impact on the primary health system.

Participants: 1168365 children including 119251 with immigrant background.

Results: The mean number of visits to PHC for nonimmigrant children was 1.40 compared with 1.19 for immigrants from high-income countries (HIC) and 1.76 for immigrants from low-income countries (LIC). Compared with non-immigrants, first generation immigrants used PHC significantly less after adjusting for age and sex (incidence risk ratio (IRR) 0.70 (HIC) to 0.93 (LIC)) while second generation immigrant children generally used $\mathrm{PHC}$ more (IRR 1.03 (HIC) to 1.43 (LIC)); however, the median number of visits were similar between all groups. The morbidity spectrum also varied between the groups.

Conclusions: Compared with non-immigrants, the excess number of consultations attributable to immigrant groups corresponds to around $1.3 \%$ of PHC visits among children.
Strengths and limitations of this study

- The study had a national coverage which avoids selection biases, and gives numbers that allow us to classify immigrants in more homogeneous groups.

- Healthcare data were collected with several quality control measures in a setting with confidentiality also minimises recall biases, social desirability and contributes to good data quality.

- Data on unregistered immigrants were not available in this study.

- The study does not include privately provided healthcare, but this type of care is used to limited degree in Norway.

- It was difficult to assess to which degree the health needs of immigrants were met.

\section{INTRODUCTION}

In 2014, nearly 60 million individuals were forcibly displaced due to conflict, violence, persecution or human right violation. ${ }^{1}$ Even if two-thirds of these were internally displaced, a large proportion was forced to leave their country. In addition, many people move between borders for other reasons. In 2014, there were estimated to be 33.5 million migrants born outside the European Union member states living within these countries, while there were 698546 immigrants in Norway in 2016 which is equivalent of $\sim 13 \%$ of the Norwegian population. ${ }^{2}$

Health status, disease spectrum and use of prescribed medication have been reported to vary among different groups of migrants and according to different phases of migration. $^{3-5}$ Also, differences in these indicators between first and second generation immigrant children have been suggested. ${ }^{6}$ Migration is an independent determinant of health, but it also interacts with other socioeconomic factors. ${ }^{3}$ Nevertheless, immigrants 
are usually reported as healthier than their peers, which is known as the healthy immigrant effect. ${ }^{78}$

Earlier studies have assessed how different groups of immigrants use primary health services, ${ }^{9}$ but fewer have reported on this for children. ${ }^{10}$ There seems to be a knowledge gap on how immigrant children from nationally representative samples use primary healthcare (PHC), differences in PHC use between first and second generation immigrant children, and morbidity spectrum among these groups. This nationwide, population-based study assesses the usage of PHC services, which in Norway includes care delivered by general practitioners (GPs) and emergency room (ER), by children with immigrant background compared with non-immigrant populations in Norway in 2008. Further, we compared morbidity spectrum between these groups.

\section{METHODS}

This study used register data from the National Population Register (NPR) in Norway, the Norwegian Health Economics Administration Database (HELFO) and Anatomical Therapeutic Chemical (ATC) codes from the Norwegian Prescription Database (NorPD) for the year 2008. ${ }^{11} 12$ These registers were linked using personal identification numbers assigned to all nonimmigrants and registered immigrants staying in Norway for at least 6 months. At the time of the study, Norway had a registered population of 4737200 of which 1168000 were children under the age of 18 years. ${ }^{13}$ Immigrants were defined as children with both parents born abroad, and were further classified into first (born abroad) and second generation (who were born in Norway, but both parents being immigrants) and according to the World Bank income categories of their parents' country of origin into low-income countries (LIC), middle-income countries (MIC) and high-income countries (HIC). ${ }^{14}$ Information regarding sex, age, country of origin for child and parents, and age at arrival in Norway was obtained from NPR.

HELFO contains administrative claims for PHC for all patient contacts based on diagnoses coded using the International Classification of Primary Care (ICPC-2) and includes both contacts with GPs and ER. Morbidity was organised through Major Expanded Diagnosis Clusters (MEDCs) using the Johns Hopkins University Adjusted Clinical Groups case-mix system (ACG System) based on diagnoses (ICPC-2) and prescription information (NorPD). ${ }^{15}$ The MEDCs group diseases in 27 broad categories (such as cardiovascular, musculoskeletal and psychosocial conditions) based on clinical, diagnostic and therapeutic similarities of the diseases and help remove differences in coding behaviour between practitioners. For each MEDC, a dichotomised variable was created indicating the presence or absence of a given MEDC for a child in 2008.

In Norway, the health system is structured around GPs providing PHC for a defined group of patients during standard working time. The GPs also provide ER health services for an extended area out-of-hours and are responsible for initial assessments of most types of diseases and injuries including investigation and treatment of patients of all ages and various degree of severity, and refer to secondary care when needed. Children in Norway under the age of 16 years are provided with free healthcare, while those above 16 years of age cover some limited costs.

\section{ANALYSIS}

Descriptive statistics including percentages and means are presented. Relative use of different types of PHC services as count variables was analysed with negative binomial regression including unadjusted models and models adjusted by age and sex. In addition, online supplementary tables also include models adjusting for morbidity as expressed by the number of chronic conditions classified with ACG. Relative risks were calculated with $95 \%$ CIs. For morbidity assessments, logistic regression models adjusted by age and sex were used to calculate ORs with CI for the presence or absence of diagnosed clusters (MEDCs) among first and second generation immigrants compared with non-immigrants. These data are presented in forest plots. The estimation of the population-attributable fraction of PHC visits if they had corresponding healthcare-seeking behaviour as non-immigrants, were based on a calculation of the difference between the actual number of PHC visits in each population group and the expected numbers of visits in each group as a product of the number of people in each group and the corresponding frequency of visits among the non-immigrants. Stata SE V.11 and SPSS V.20.0 were used for statistical analysis.

The Norwegian Social Science Data Service prepared the final pseudoanonymised data file.

\section{RESULTS}

Our data comprised 926044 children born in Norway of Norwegian parents and 119251 immigrant children, of which 49014 were first generation and 70237 were second generation immigrants (see table 1 and online supplementary file). Among the immigrants, 22234 originated from LIC, 69333 from MIC and 27684 from HIC. In addition, 123070 children had a mixed background (eg, children with at least one Norwegian parent), and are not presented in the analyses below. The sex distribution was similar for immigrants and nonimmigrants. The mean age of immigrant children, particularly those from LIC (8.2), was slightly lower than that of non-immigrants (9.3).

The mean number of visits to PHC services including GPs, and ER services ranged from 1.19 for HIC children to 1.76 for immigrants from LIC (table 2); however, the median number of visits to PHC were similar between all the groups with differences seen in the 75th and 90th centiles (see online supplementary file). Some of 
Table 1 Background characteristics of the population included

\begin{tabular}{|c|c|c|c|c|c|c|c|c|c|c|}
\hline & \multicolumn{2}{|c|}{ Non-immigrants } & \multicolumn{2}{|l|}{ HIC } & \multicolumn{2}{|l|}{ MIC } & \multicolumn{2}{|l|}{ LIC } & \multicolumn{2}{|l|}{ Total } \\
\hline & $\mathbf{n}$ & Per cent & $\mathrm{n}$ & Per cent & $\mathrm{n}$ & Per cent & $\mathrm{n}$ & Per cent & $\mathbf{n}$ & Per cent \\
\hline \multicolumn{11}{|l|}{ Sex of child } \\
\hline Boy & 475250 & 51 & 14120 & 51 & 35414 & 51 & 11471 & 52 & 536255 & 51 \\
\hline Girl & 450794 & 49 & 13564 & 49 & 33919 & 49 & 10763 & 48 & 509040 & 49 \\
\hline \multicolumn{11}{|l|}{ Age of child (years) } \\
\hline $0-2$ & 91127 & 10 & 3726 & 13 & 7134 & 10 & 2980 & 13 & 104967 & 10 \\
\hline $2-5$ & 135071 & 15 & 5109 & 18 & 11096 & 16 & 4079 & 18 & 155355 & 15 \\
\hline $5-10$ & 233934 & 25 & 7148 & 26 & 18449 & 27 & 5663 & 25 & 265194 & 25 \\
\hline $10-18$ & 465912 & 50 & 11701 & 42 & 32654 & 47 & 9512 & 43 & 519779 & 50 \\
\hline \multicolumn{11}{|l|}{ Immigrant category } \\
\hline Non-immigrant & 926044 & 100 & & & & & & & & \\
\hline First generation & & & 17879 & 65 & 19958 & 29 & 11177 & 50 & 49014 & 41 \\
\hline $\begin{array}{l}\text { Second } \\
\text { generation }\end{array}$ & & & 9805 & 35 & 49375 & 71 & 11057 & 50 & 70237 & 59 \\
\hline \multicolumn{11}{|l|}{ Area of origin } \\
\hline $\begin{array}{l}\text { Asia, Africa and } \\
\text { Latin America }\end{array}$ & & & 2049 & 7 & 57637 & 83 & 22234 & 100 & 81920 & 8 \\
\hline $\begin{array}{l}\text { North America } \\
\text { and Oceania }\end{array}$ & & & 822 & 3 & 3 & 0 & & & 825 & 0 \\
\hline Nordic countries & & & 4885 & 18 & & & & & 4885 & 0 \\
\hline Norway & 926044 & 100 & & & & & & & 926044 & 89 \\
\hline Western Europe & & & 7012 & 25 & & & & & 7012 & 1 \\
\hline Eastern Europe & & & 12916 & 47 & 11693 & 17 & & & 24609 & 2 \\
\hline
\end{tabular}

Table 2 Mean number of visits to GP, ER healthcare and combined primary healthcare (GP and ER) among children in Norway in 2008

\begin{tabular}{|c|c|c|c|}
\hline & Use of GP & Use of ER & $\begin{array}{l}\text { Primary } \\
\text { care use }\end{array}$ \\
\hline Non-immigrants & 1.23 & 0.18 & 1.40 \\
\hline \multicolumn{4}{|c|}{ First and second generations combined } \\
\hline $\mathrm{HIC}$ & 1.05 & 0.14 & 1.19 \\
\hline MIC & 1.41 & 0.25 & 1.66 \\
\hline LIC & 1.53 & 0.23 & 1.76 \\
\hline \multicolumn{4}{|l|}{ First generation } \\
\hline $\mathrm{HIC}$ & 0.86 & 0.11 & 0.96 \\
\hline MIC & 0.99 & 0.13 & 1.12 \\
\hline LIC & 1.12 & 0.11 & 1.24 \\
\hline \multicolumn{4}{|c|}{ Second generation } \\
\hline $\mathrm{HIC}$ & 1.39 & 0.21 & 1.60 \\
\hline MIC & 1.59 & 0.29 & 1.88 \\
\hline LIC & 1.95 & 0.34 & 2.29 \\
\hline \multicolumn{4}{|c|}{$\begin{array}{l}\text { Immigrants grouped according to country of origin of children and } \\
\text { parents in line with the World Bank income categories into LIC, } \\
\text { MIC and HIC and by first and second generations (combined and } \\
\text { separately). } \\
\text { ER, emergency room; GP, general practitioner; HIC, high-income } \\
\text { countries; LIC, low-income countries; MIC, middle-income } \\
\text { countries. }\end{array}$} \\
\hline
\end{tabular}

the differences were attributed to differences in age (table 3). First generation immigrants used PHC less compared with non-immigrants when adjusting for age and sex, while second generation immigrants generally used PHC more. There were no differences in the number of PHC visits among immigrant girls and boys. The results were similar when restricting the analyses to children $<10$ years of age (see online supplementary file).

Regarding morbidity spectrum, diseases and symptoms related to respiratory tract infections, renal, oral and gastrointestinal conditions, eczema, fever and nausea were more frequently presented among second generation immigrants compared with non-immigrants, while only nausea and gastrointestinal conditions were presented more frequently presented among first generation immigrants compared with non-immigrants (see figures 1 and 2 and online supplementary file). Among non-immigrants, attention-deficit disorder and anxiety, allergy and asthma, neurological, musculoskeletal and rheumatic conditions were more frequently presented compared with among immigrants.

The total number of PHC visits for children in Norway with immigrant and non-immigrant background during 2008 was 1486907 (table 4). Compared with nonimmigrants, the excess number of consultations attributable to all immigrant groups combined was 19967 . This corresponds to $1.3 \%$ of the combined PHC consultations among children (1.2\% of GP visits and $2.6 \%$ of ER visits).

\section{DISCUSSION}

This study showed significant differences in PHC usage among non-immigrants and the different groups of 
Table 3 Relative use of GP's healthcare, ER healthcare and combined PHC including GP and ER reported as IRRs with $95 \% \mathrm{Cls}$ assessed with negative binomial regression models unadjusted and also adjusting for age and sex

\begin{tabular}{|c|c|c|c|}
\hline & $\begin{array}{l}\text { Use of GP } \\
\text { IRR (CI) }\end{array}$ & $\begin{array}{l}\text { Use of ER } \\
\text { IRR (CI) }\end{array}$ & $\begin{array}{l}\text { Use of PHC } \\
\text { IRR (CI) }\end{array}$ \\
\hline \multicolumn{4}{|c|}{ Model 1: unadjusted results, first generation only } \\
\hline Non-immigrants (reference) & 1 & 1 & 1 \\
\hline $\mathrm{HIC}$ & 0.70 (0.68 to 0.72$)$ & $0.60(0.57$ to 0.63$)$ & 0.69 (0.67 to 0.70$)$ \\
\hline MIC & 0.81 (0.79 to 0.82$)$ & $0.75(0.72$ to 0.79$)$ & 0.80 (0.78 to 0.82$)$ \\
\hline LIC & 0.91 (0.89 to 0.94$)$ & 0.65 (0.61 to 0.69$)$ & 0.88 (0.86 to 0.90$)$ \\
\hline \multicolumn{4}{|c|}{ Model 2: unadjusted results, second generation only } \\
\hline Non-immigrants (reference) & 1 & 1 & 1 \\
\hline $\mathrm{HIC}$ & $1.13(1.10$ to 1.16$)$ & 1.20 (1.13 to 1.27$)$ & $1.14(1.11$ to 1.17$)$ \\
\hline MIC & $1.29(1.28$ to 1.31$)$ & 1.65 (1.61 to 1.69$)$ & $1.34(1.32$ to 1.36$)$ \\
\hline LIC & 1.59 (1.56 to 1.63$)$ & $1.92(1.83$ to 2.01$)$ & $1.63(1.60$ to 1.67$)$ \\
\hline \multicolumn{4}{|c|}{ Model 3: adjusted by age and sex, first generation only } \\
\hline Non-immigrants (reference) & 1 & 1 & 1 \\
\hline $\mathrm{HIC}$ & 0.71 (0.69 to 0.72$)$ & $0.61(0.58$ to 0.64$)$ & $0.70(0.68$ to 0.71$)$ \\
\hline $\mathrm{MIC}$ & 0.87 (0.85 to 0.89$)$ & 0.87 (0.83 to 0.91$)$ & 0.87 (0.85 to 0.89$)$ \\
\hline LIC & $0.96(0.93$ to 0.98$)$ & $0.72(0.67$ to 0.77$)$ & $0.93(0.90$ to 0.95$)$ \\
\hline \multicolumn{4}{|c|}{ Model 4: adjusted by age and sex, second generation only } \\
\hline Non-immigrants (reference) & 1 & 1 & 1 \\
\hline $\mathrm{HIC}$ & $1.03(1.00$ to 1.06$)$ & $1.00(0.94$ to 1.06$)$ & $1.03(1.00$ to 1.06$)$ \\
\hline MIC & $1.23(1.21$ to 1.24$)$ & 1.47 (1.44 to 1.51$)$ & 1.26 (1.25 to 1.27$)$ \\
\hline LIC & 1.41 (1.38 to 1.45$)$ & 1.53 (1.46 to 1.60$)$ & $1.43(1.40$ to 1.46$)$ \\
\hline
\end{tabular}

Categories of immigration is grouped according to country of origin of children and parents in line with the World Bank income categories into $\mathrm{LIC}, \mathrm{MIC}$ and $\mathrm{HIC}$ for first and second generations separately.

ER, emergency room; GP, general practitioner; HIC, high-income countries; IRR, incidence risk ratio; LIC, low-income countries; MIC, middleincome countries; PHC, primary healthcare.

registered immigrant children living in Norway, but the differences were almost balanced out between different immigrant groups on the system level. First generation immigrant children used PHC services significantly less than non-immigrants, while PHC use was significantly higher among second generation immigrant children. The difference was mainly driven by a minority among second generation immigrant children. The total differences in use of PHC services among immigrants contribute to $1.3 \%$ of the PHC consultations, proportionally more for ER than GP services. The distribution of symptoms and health problems differed between first and second generation immigrants and non-immigrants.

The observed differences in healthcare use might be related to several factors. First, the language and cultural barriers between migrants and GPs could translate into a need for several consultations required to provide similar healthcare services, independent on whether a translator is used. ${ }^{16}$ There are also indications that healthcare providers to limited degree are trained to meet the more complex needs of refugees, ${ }^{17}$ and thus immigrants may to a larger degree need to consult physicians several times for the same health problem if initially unsolved. In addition, to limit spread of communicable diseases, new migrants undergo routine screening of some infectious diseases which might contribute to a proportion of the consultations, although much of this happens outside standard PHC. ${ }^{18}$ A recent assessment in hospitals and secondary healthcare in Norway shows relatively similar patterns with only minor differences in healthcare use among children. ${ }^{19}$ It could be assumed that some few families migrate to seek improved medical care for severely sick children. However, in accordance to previous studies, our data indicate that if this is the case, it does not contribute to a large burden for the health system. 'The healthy immigrant effect' reported mostly among adults ${ }^{78}$ is probably more relevant for first generation immigrant children than for second generation immigrant children who are not born in their parents' country of origin. Similar patterns of PHC usage for children and adults is not surprising as parents often have a strong degree of influence on when their children should seek healthcare. ${ }^{20}$ Increasing length of stay is also likely that to be linked with increasing adoption of culture and behavioural patterns from the new country of residence.

Immigrants' health can be influenced by emotional stress related to challenges at the individual, familial and societal levels. ${ }^{721}$ This includes fear of deportation, discrimination, linguistic and cultural difficulties, family, relatives and friends living in uncertainty, changing between different educational systems, obstacles in accessing healthcare and the right to work. The influence of these factors on heath seems to be particularly relevant for refugees who have experienced torture and other potentially traumatic events who are at increased risk of post-traumatic stress disorder and depression. ${ }^{22}$ A systematic review of serious mental health disorders in refugees 


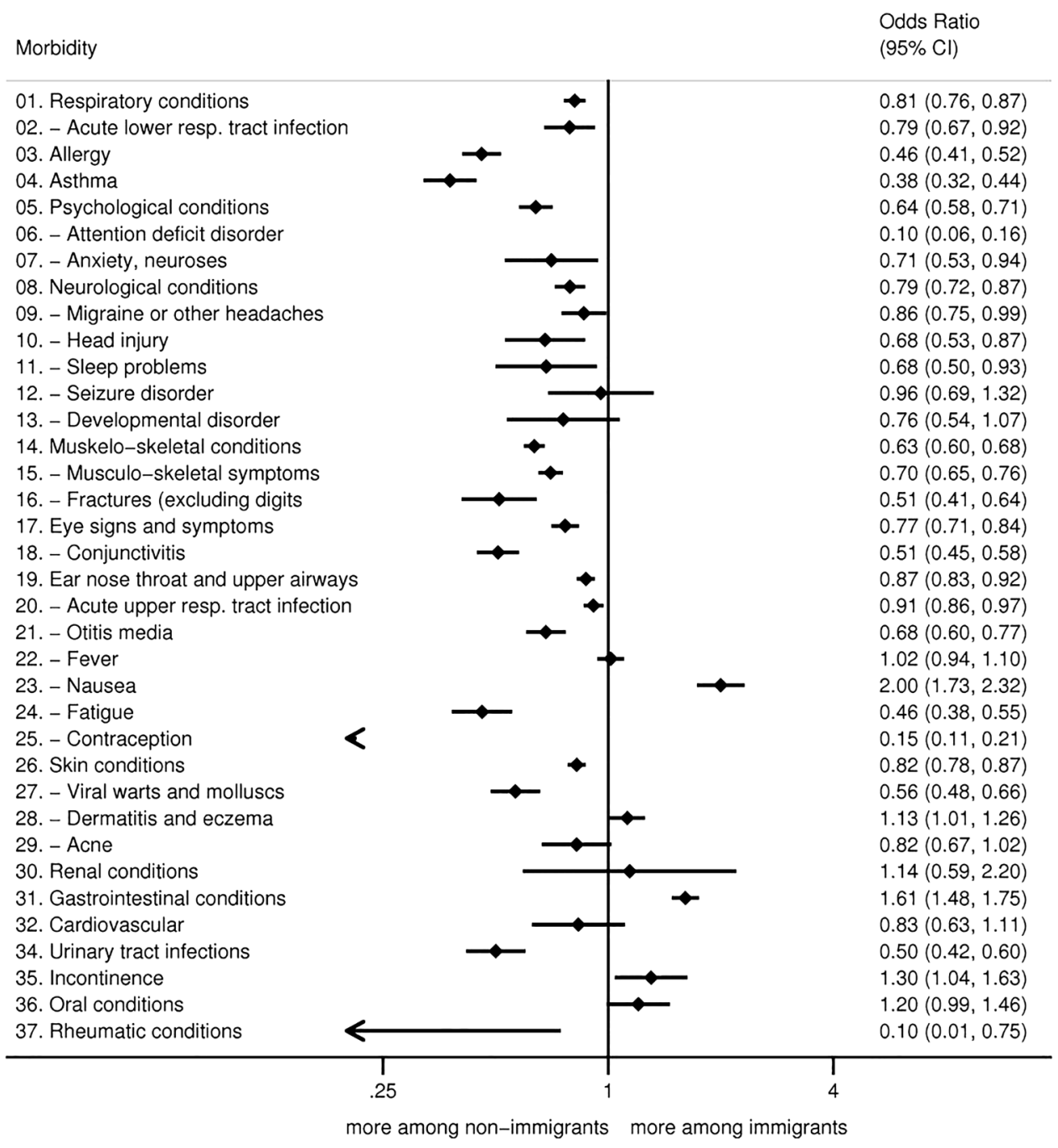

Figure 1 Forest plot presenting differences in diagnosed morbidity adjusted for age and sex reported as ORs with $95 \% \mathrm{Cls}$ assessed with logistic regression models. Comparison between non-immigrants (reference) and immigrants from low-income countries including first generation only.

in Western countries indicated a substantially increased burden, with around $11 \%$ of the children suffering from post-traumatic stress disorder. ${ }^{23}$ We did not find any increase but rather substantially lower rates of mental health disorders diagnosed among immigrants. This corresponds well to a study among adult immigrants in Norway as well as findings from Spain. ${ }^{24} 25$ There could be several explanations for this. On the one side, cultural differences including differences in family structure could make immigrants less vulnerable for severe mental health suffering, mental health conditions among children could be less acknowledged in immigrants or the mental health suffering might be reported in a way which is less often recognised among physicians in Norway. ${ }^{21}{ }^{26}$ On the other side, mental suffering can be presented through symptoms such as nausea or gastrointestinal symptoms, often referred to as somatisation, which can again have varying forms in different ethnic groups. ${ }^{27}$ Accordingly, Kirmayer ${ }^{26}$ has argued that mental suffering has various presentations in different cultures, and that variances in somatisation could be due to misclassification and insufficient cultural understanding of how mental health suffering is presented. These mechanisms could also explain the higher relative frequency of non-specific and gastrointestinal symptoms and conditions among immigrant children from LIC. Finally, it is also possible that healthcare in Norway is more focused and trained to identify some health conditions, for example, attention-deficit disorders and to a lesser degree recognise suffering from post-traumatic stress disorder among children, with the latter probably being more common among refugees. ${ }^{22}$

Respiratory tract infections were also more commonly presented among immigrants. This could be explained by immigrant children often having more siblings and living in smaller housing compared with nonimmigrants, as crowding could increase the risk of, for example, respiratory tract infections ${ }^{28}$ but could also be linked with differences in health seeking behaviour. This study also showed substantial differences in use of 


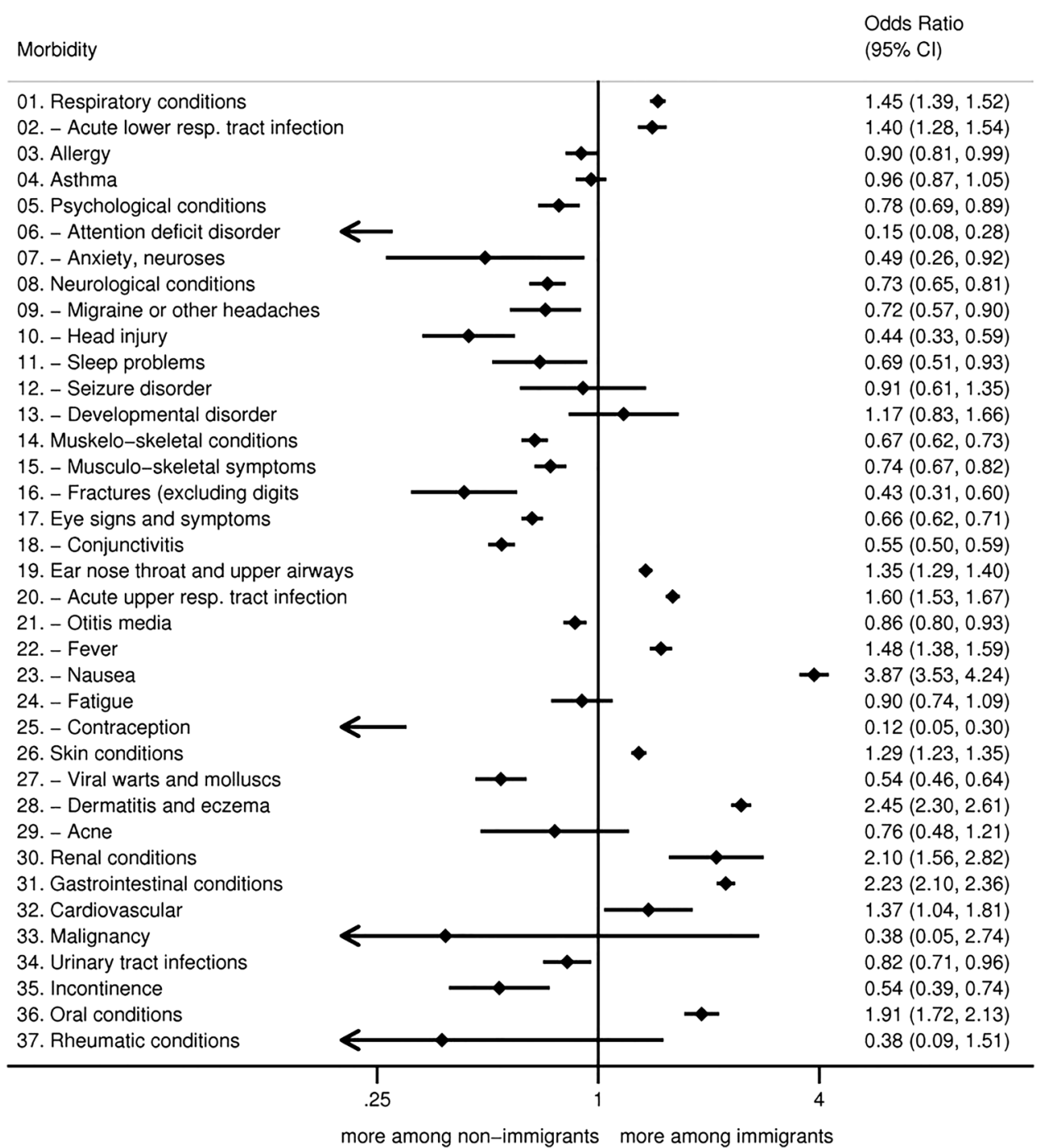

Figure 2 Forest plot presenting differences in diagnosed morbidity adjusted for age and sex reported as ORs with $95 \% \mathrm{Cls}$ assessed with logistic regression models. Comparison between non-immigrants (reference) and immigrants from low-income countries including second generation only.

Table 4 Total number of primary healthcare visits among children in Norway including use of GP's healthcare, ER healthcare and total combined primary healthcare including GP and ER and differences $(\Delta)$ in healthcare use compared with non-immigrants

\begin{tabular}{|c|c|c|c|c|c|c|c|}
\hline & Population & GP visits & ER visits & Total visits & $\Delta$ GP visits & $\Delta$ ER visits & $\Delta$ Total visits \\
\hline Non-immigrants & 926044 & 1135251 & 164335 & 1299586 & 0 & 0 & 0 \\
\hline \multicolumn{8}{|c|}{ Immigrated (parents and child born abroad, first generation) } \\
\hline HIC & 17879 & 15342 & 1893 & 17235 & -6576 & -1280 & -7856 \\
\hline MIC & 19958 & 19750 & 2656 & 22406 & -4717 & -886 & -5603 \\
\hline LIC & 11177 & 12519 & 1285 & 13804 & -1183 & -698 & -1882 \\
\hline \multicolumn{8}{|c|}{ Parents immigrated, child born in Norway (second generation) } \\
\hline $\mathrm{HIC}$ & 9805 & 13606 & 2090 & 15696 & 1586 & 350 & 1936 \\
\hline MIC & 49375 & 78355 & 14470 & 92825 & 17825 & 5708 & 23533 \\
\hline LIC & 11057 & 21590 & 3765 & 25355 & 8035 & 1803 & 9838 \\
\hline Total & 1045295 & 1296413 & 190494 & 1486907 & 14970 & 4997 & 19967 \\
\hline $\begin{array}{l}\Delta \text { in per cent compared with } \\
\text { non-immigrants }\end{array}$ & & & & & $1 \%$ & $3 \%$ & $1 \%$ \\
\hline
\end{tabular}


contraceptives among immigrants under age of 18 years compared with non-immigrants. Similar findings have also been reported among adults. ${ }^{29}$ There could be different reasons for this including differences in age of sexual debut, differences in use of barrier contraception including condoms, differences in use of natural preventive strategies such as 'safe periods', different cultural views on contraceptives and different views in importance of family planning.

Other studies have suggested that difficulties in accessing standard PHC services could lead to increased use of ER healthcare. ${ }^{10}{ }^{30}$ Our results showed that first generation immigrants used ER healthcare less often than non-immigrants, while second generation immigrants generally used both types of PHC services more often than non-immigrants, with greater differences for use of ER healthcare for second generation immigrant children from LIC. To the best of our knowledge, there are no other studies comparing PHC services among first and second generation immigrant children, and it could be useful for future studies to investigate whether the same patterns are seen in other countries.

Our study has several strengths including its national coverage, which avoids selection biases, and gives numbers that allow us to classify immigrants in more homogeneous groups, although heterogeneity inside groups still exists. The use of healthcare registered data collected with several quality control measures in a setting with confidentiality also minimises recall biases, social desirability and contributes to good data quality for many of the included variables. However, our study also has some limitations. As it is based on national registers, unregistered immigrants, whose healthcare access is likely to be lower, ${ }^{31}$ are not included. It is also difficult to assess to which degree the health needs of immigrants are met. Even though we have several hypotheses on the reasons for the observed differences in PHC usage, we cannot verify to which degree the various causes contribute. Some variables that could have been useful, such as sociodemographic variables of the family and length of stay of parents, were not possible to link to the children included. Data on these among adults in Norway show that immigrants particularly from LIC more often had a lower income and education than nonimmigrants. ${ }^{32}$ We would expect the same to be true for the parents of the included children, partly explaining their higher use of PHC. The morbidity estimates are based on ICPC-2 diagnosis codes reported for administrative claims, in which often only one diagnosis is reported per visit even in the presence of more than one disease. However, ICPC-2 codes have been widely used and validated for comparison of populations, ${ }^{33}$ and as we do not use them to calculate prevalence of diseases, this is unlikely to cause substantial biases in the presented data. Our study does not include privately provided healthcare, but this type of care is used to limited degree in Norway where public health insurance covers $85 \%$ of health spending. ${ }^{34}$ Still, it is possible that there is an opposite pattern in private healthcare use balancing out the small differences in PHC usage between immigrants and non-immigrants.

In conclusion, first generation immigrant children in Norway use PHC services less than non-immigrants when taking slight differences in age distribution into account. Second generation immigrants generally have somewhat higher use of PHC services, mainly driven by a minority within the group. The difference in PHC usage among children with immigrant background contributes to only $1.3 \%$ of the PHC visits among children compared with the non-immigrant population in Norway. There were some differences in conditions they sought healthcare for.

Contributors LTF was involved in design, implementation, analysis, interpretation and writing. KAM was involved in interpretation and co-writing. ED was involved in design, implementation, analysis, interpretation and co-writing.

Funding LTF and ED were employed by the University of Bergen and KAM was funded by the Norwegian Cancer Society.

Competing interests None declared.

Ethics approval This study is part of the project 'Immigrants' health in Norway' which was approved by the Regional Committee for Medical and Health Research Ethics, the Norwegian Data Inspectorate, the Norwegian Labour Welfare Service and the Norwegian Directorate of Health.

Provenance and peer review Not commissioned; externally peer reviewed.

Data sharing statement No additional data are available.

Open Access This is an Open Access article distributed in accordance with the Creative Commons Attribution Non Commercial (CC BY-NC 4.0) license, which permits others to distribute, remix, adapt, build upon this work noncommercially, and license their derivative works on different terms, provided the original work is properly cited and the use is non-commercial. See: http:// creativecommons.org/licenses/by-nc/4.0/

\section{REFERENCES}

1. United Nations High Commissioner for Refugees (UNHCR). Forced displacement in 2014. UNHCR Global Trends, 2015.

2. Statistics Norway (Statistisk sentralbyrå). Immigrants and Norwegian-born to immigrant parents. http://www.ssb.no/en/ befolkning/statistikker/innvbef

3. Rechel B, Mladovsky $\mathrm{P}$, Ingleby $\mathrm{D}$, et al. Migration and health in an increasingly diverse Europe. Lancet 2013;381:1235-45.

4. Wolfe I, Thompson M, Gill P, et al. Health services for children in Western Europe. Lancet 2013;381:1224-34.

5. Gimeno-Feliu LA, Armesto-Gómez J, Macipe-Costa R, et al. Comparative study of paediatric prescription drug utilization between the Spanish and immigrant population. BMC Health Serv Res 2009;9:225.

6. Balcazar AJ, Grineski SE, Collins TW. The Hispanic health paradox across generations: the relationship of child generational status and citizenship with health outcomes. Public Health 2015;129:691-7.

7. Linton JM, Choi R, Mendoza F. Caring for children in immigrant families: vulnerabilities, resilience, and opportunities. Pediatr Clin North Am 2016;63:115-30.

8. Gimeno-Feliu LA, Calderón-Larranaga A, Diaz E, et al. The healthy migrant effect in primary care. Gac Sanit 2015;29:15-20.

9. Uiters $\mathrm{E}$, Devillé W, Foets $\mathrm{M}$, et al. Differences between immigrant and non-immigrant groups in the use of primary medical care; a systematic review. BMC Health Serv Res 2009;9:76.

10. Ballotari $P, D^{\prime}$ Angelo $S$, Bonvicini $L$, et al. Effects of immigrant status on emergency room (ER) utilisation by children under age one: a population-based study in the province of Reggio Emilia (Italy). BMC Health Serv Res 2013;13:458.

11. Statistics Norway (Statistisk sentralbyrå). Classification of centrality, 2013. http://www.ssb.no/metadata/conceptvariable/vardok/927/en 
12. Furu K. Establishment of the nationwide Norwegian Prescription Database (NorPD) - new opportunities for research in pharmacoepidemiology in Norway. Norw J Epidemiol 2008:18:129-36.

13. Statistics Norway (Statistisk sentralbyrå). Population, 2008. http://ssb.no/en/befolkning/statistikker/folkemengde/aar/ 2008-03-13

14. World Bank. New country classifications 2013, 2013. http://data. worldbank.org/news/new-country-classifications

15. Health Services Research \& Development Center. The Johns Hopkins ACG System. Technical Reference Guide Version 10.0. In: Weiner JP, Abrams C, eds. The Johns Hopkins ACG System. Technical Reference Guide Version 10.0. Baltimore, MD: Johns Hopkins Bloomberg School of Public Health, 2011. https://www. healthpartners.com/ucm/groups/public/@hp/@public/documents/ documents/cntrb_035024.pd

16. Karliner LS, Jacobs EA, Chen AH, et al. Do professional interpreters improve clinical care for patients with limited English proficiency? A systematic review of the literature. Health Serv Res 2007;42: $727-54$.

17. Adams KM, Gardiner LD, Assefi N. Healthcare challenges from the developing world: post-immigration refugee medicine. $B M J$ 2004;328:1548-52.

18. Norwegian Directorate of Health (Helsedirektoratet). Asylsøkere, flyktninger og familiegjenforente. Veileder for helsetjenestetilbudet til asylsøkere, flyktninger og familiegjenforente (Guidelines for the health care services for asylum seekers, refugees and family reunification). 2015. https://helsedirektoratet.no/retningslinjer/ asylsokere-flyktninger-og-familiegjenforente

19. Elstad JI, Finnvold JE, Texmon I. Bruk av sykehus og spesialisthelsetjenester blant innbyggere med norsk og utenlandsk bakgrunn. NOVA Rapport 10/2015: Norsk institutt for forskning om oppvekst, velferd og aldring, 2015:155.

20. Coyne I. Children's participation in consultations and decision-making at health service level: a review of the literature. Int J Nurs Stud 2008;45:1682-9.

21. American Psychological Association (APA) Presidential Task Force on Immigration. Crossroads: The psychology of immigration in the new century. 2012. http://www.apa.org/topics/ immigration/report.aspx
22. Steel Z, Chey T, Silove D, et al. Association of torture and other potentially traumatic events with mental health outcomes among populations exposed to mass conflict and displacement: a systematic review and meta-analysis. JAMA 2009;302:537-49.

23. Fazel M, Wheeler J, Danesh J. Prevalence of serious mental disorder in 7000 refugees resettled in western countries: a systematic review. Lancet 2005;365:1309-14.

24. Straiton M, Reneflot A, Diaz E. Immigrants' use of primary health care services for mental health problems. BMC Health Serv Res 2014; 14:341.

25. Macipe-Costa RM, García-Campayo J, Gimeno-Feliu LA, et al. Differences in methylphenidate use between immigrants and Spaniards in the child population of Aragon, Spain: a retrospective study. J Child Neurol 2011;26:1265-70.

26. Kirmayer LJ. Cultural variations in the clinical presentation of depression and anxiety: implications for diagnosis and treatment. J Clin Psychiatry 2001;62(Suppl 13):22-8; discussion 29-30.

27. Aragona $\mathrm{M}$, Rovetta $\mathrm{E}$, Pucci $\mathrm{D}$, et al. Somatization in a primary care service for immigrants. Ethn Health 2012;17:477-91.

28. Colosia AD, Masaquel A, Hall CB, et al. Residential crowding and severe respiratory syncytial virus disease among infants and young children: a systematic literature review. BMC Infect Dis 2012;12:95.

29. Omland G, Ruths S, Diaz E. Use of hormonal contraceptives among immigrant and native women in Norway: data from the Norwegian Prescription Database. BJOG 2014;121:1221-8.

30. Sandvik H, Hunskaar S, Diaz E. Immigrants' use of emergency primary health care in Norway: a registry-based observational study. BMC Health Serv Res 2012;12:308.

31. Karlsen MA. Precarious inclusion. Irregular migration, practices of care, and state bordering in Norway. University of Bergen, 2015.

32. Diaz E, Gimeno-Feliu LA, Calderón-Larrañaga A, et al. Frequent attenders in general practice and immigrant status in Norway: a nationwide cross-sectional study. Scand J Prim Health Care 2014:32:232-40.

33. Frese $\mathrm{T}$, Herrmann $\mathrm{K}$, Bungert-Kahl $\mathrm{P}$, et al. Inter-rater reliability of the ICPC-2 in a German general practice setting. Swiss Med Wkly 2012;142:w13621.

34. Statistics Norway (Statistisk sentralbyrå). Health accounts, 2015. https://www.ssb.no/en/nasjonalregnskap-og-konjunkturer/statistikker/ helsesat/aar/2016-03-14 